Trab.Ling.Aplic., Campinas, (43): 171-183, Jan./Jun. 2004

\title{
O LUGAR DA LÍNGUA MATERNA NA CONSTITUIÇÃO IDENTITÁRIA DO SUJEITO BILÍNGÜE ${ }^{1}$
}

\author{
JULIANA SANTANA CAVALLARI ${ }^{2}$ \\ (Doutoranda em Lingüística Aplicada - UNICAMP)
}

\begin{abstract}
The purpose of this paper is to analyze and comprehend the position of the mother tongue (Portuguese) in the construction of the identity of bilingual subjects, taking into account the strong presence of English as a foreign language in our society. The answers given by four bilingual subjects to a questionnaire designed for this study were analyzed. The discursive analysis of the data shows that the contact between the mother tongue and the foreign language affects the imaginary representations about both languages, as well as the representations about their speakers.
\end{abstract}

Keywords: mother tongue, bilingual subjects, discursive analysis.

\section{INTRODUÇÃO}

Na sociedade brasileira contemporânea, o lugar discursivamente construído da língua inglesa (LI) como lugar de poder e que propicia a ascensão social está bem definido, colocando em funcionamento um imaginário em relação à LI. Desse modo, a forte presença da LI em nosso meio assegura a circulação de representações que passam a fazer parte da constituição identitária do sujeito da língua materna (LM).

Acreditamos que mesmo aqueles que não são fluentes na LI também sejam afetados pelos sons e dizeres desta língua, propagados através de músicas e programas televisivos, radiofônicos ou cibernéticos que, dentre outras coisas, reforçam o lugar ocupado pela LI.

Tendo em mente as considerações anteriores, procuraremos compreender, com base na análise de enunciados formulados por quatro sujeitos bilíngües, o lugar ocupado pela LM na constituição identitária desses sujeitos. Para tanto, acreditamos ser relevante rastrear, na superfície lingüística, o imaginário em relação à LM contraposto ao imaginário em relação à LI, atentando para o fato de que o contato do enunciador com uma língua estrangeira (LE), no caso a LI, afeta e desloca o lugar ocupado pela LM, provocando efeitos na constituição identitária do sujeito. Vale destacar que, para este estudo, tomaremos como sujeito bilíngüe aquele que é capaz de interagir com falantes da LM e da LI, mas que

${ }^{1}$ Este artigo resultou de um trabalho de qualificação em Lingüística Aplicada, na área de EnsinoAprendizagem de Língua Materna, sob a orientação da Profa. Dra. Claudete Moreno Ghiraldelo.

${ }^{2}$ Doutoranda em Lingüística Aplicada na área de Ensino-Aprendizagem de LE/L2; bolsista FAPESP. 
aprendeu a LI já na idade adulta, ou seja, após ter adquirido a LM, e não aquele que adquiriu, simultaneamente, a LM e uma LE, quando criança.

Do ponto de vista teórico, o presente trabalho situa-se na interface entre a perspectiva discursiva, segundo Foucault, e alguns conceitos psicanalíticos.

\section{ALGUNS CONCEITOS NORTEADORES}

\subsection{Estatutos de língua: trilhando um conceito de língua materna}

Neste item do trabalho, trilharemos um conceito de LM que norteará a análise e discussão dos registros apresentados a seguir. Em função do tema abordado neste estudo, fez-se necessário, ainda, pensarmos sobre o conceito de LI que provoca efeitos de sentido nas formulações postas, uma vez que se trata de enunciados proferidos por sujeitos bilíngües. A partir da relação estabelecida entre a LM e a LI, esboçaremos um conceito de LM que apontará para a constituição identitária do sujeito bilíngüe, não perdendo de vista a relação constitutiva deste sujeito com ambas as línguas.

Partiremos do princípio de que a LM e a LE ocupam estatutos distintos, já que incidem diferentemente sobre a constituição subjetiva do sujeito bilíngüe. Entendemos, com base em Milner (1987), que a LM é sempre posta como estatuto de uma língua particular, pois o sujeito se constitui na/pela LM. Pereira de Castro (1998) argumenta na mesma direção e acrescenta que a aquisição da LM é uma experiência inaugural e definitiva, considerando que é pela LM que um corpo não falante (infans) passa a ser um sujeito falante ou de linguagem. Se pensarmos que alguém se torna falante como efeito da LM ou, ainda, que é a LM que constitui a base psíquica do ser, como já sugerido por Revuz (1998), então a LE não terá jamais o mesmo estatuto da LM, embora seja capaz de colocar o sujeito em contato com outras discursividades, afetando suas representações identitárias, bem como o lugar ocupado pela LM.

Adentrando a relação entre a LM e a LE, Melman (1992), a partir de uma perspectiva psicanalítica, contribui para essa discussão ao afirmar que a LM é o lugar de interdição, já que interdita ou barra o sujeito, por carregar, em si, o peso da história deste sujeito. Sendo assim, "tudo não é possível de se dizer" (Milner, 1987), pois a língua é o espaço onde o desejo inconsciente se deposita, produzindo equívocos e efeitos de sentido que escapam ao próprio sujeito enunciador.

Em contrapartida, a LE é, imaginariamente, o lugar em que quase tudo é permitido e pode ser dito. Mais especificamente, o sujeito que entra em contato com uma LE tem a sensação de 'tudo poder dizer' e de não ser "barrado" por essa língua outra que, aparentemente, não possui o mesmo "peso" nem a mesma "censura" instaurada na/pela LM. Conseqüentemente, muda-se de lugar subjetivo com a mudança de língua, ou seja, a subjetividade na LM não é a mesma na LE. A relação entre a LM e a LE, portanto, é uma relação de confronto e de "contaminação", tendo em vista que, segundo Revuz (1998:215), "toda tentativa de tentar aprender uma outra língua vem perturbar, questionar, modificar aquilo que está inscrito em nós com as palavras dessa primeira língua”. 
Antes de passarmos para a análise dos registros, é significativo discorrermos sobre as concepções de identidade e de identificação que as embasarão, lembrando que estaremos problematizando o lugar da LM na constituição identitária do sujeito bilíngüe.

\subsection{Identidade e Identificação}

Segundo as concepções de identidade e de identificação que direcionam este estudo e que se inserem numa perspectiva discursiva, perpassada por algumas noções psicanalíticas, a identidade é sempre imaginária, já que põe em funcionamento as imagens que o sujeito faz de si mesmo, a partir de imagens lançadas pelo olhar do outro e que permitem a ele se reconhecer enquanto tal. Assim sendo, as representações identitárias, sustenta Costa (2001), possibilitam ao sujeito reconhecer-se, através do que é discursivamente construído como contorno para o "si mesmo".

As considerações anteriores dialogam com os estudos de Hall (2000). O autor enfatiza que as identidades são construídas por meio da diferença, ou seja, por meio da relação com o Outro, da relação com aquilo que não é ou aquilo que falta. O autor (op.cit.:118) utiliza o termo identidade

para significar o ponto de encontro, o ponto de sutura, entre, por um lado, os discursos e as práticas que tentam nos interpelar, nos falar ou nos convocar para que assumamos nossos lugares como sujeitos sociais de discursos particulares e, por outro lado, os processos que produzem subjetividade, que nos constroem como sujeitos aos quais se pode falar.

Esse esclarecimento do autor evidencia o fato de ser por meio de práticas discursivas que se constroem identidades que são diferentes das demais, lembrando que o sujeito se reconhece em múltiplas identidades, conforme a posição discursiva que ocupa. Isso faz com que a identidade seja sempre múltipla ou híbrida, como já proposto por Silva (2000). Entendemos, a partir da leitura de Hall (2000:108), que "as identidades são, pois, pontos de apego temporário às posições de sujeito que as práticas discursivas constroem para nós".

As identificações, por sua vez, são necessárias para construir “pertenças”, isto é, para situar o sujeito no mundo e nas relações sociais. As múltiplas identificações, dissolvidas em traços que já se encontram impressos no sujeito, ao mesmo tempo em que determinam o lugar discursivo do sujeito enunciador, também (des)estabilizam sua identidade, justamente por serem múltiplas e transitórias as identificações. Por este viés, Hall (2000:62) afirma que "as identificações são os mecanismos pelos quais são construídas as identidades que, fragmentadas, estão em constante movimento".

Ainda dentro de uma leitura psicanalítica, Chnaiderman (1998:48) observa que:

o termo identificação vem sendo utilizado para definir processos estruturantes que ocorrem no EU (ou Ego, dependendo do autor consultado) através dos quais este internaliza relações com o mundo circundante, dando lugar a matrizes identificatórias.

Portanto, podemos dizer que as identificações desestabilizam o sujeito ao invés de estabilizá-lo: são a sedimentação de nós e dos "nós” na constituição de qualquer Eu. 


\section{COLETA DOS REGISTROS}

Para coleta do corpus deste trabalho, foi utilizado um questionário (anexo) contendo quinze perguntas que foram respondidas, por escrito, por quatro sujeitos bilíngües. As perguntas foram elaboradas de modo a mobilizar os entrevistados a discursivizarem não só sobre a LM, mas também sobre a LE, já que abordavam suas experiências enquanto bilíngües. Como bem demonstra Ghiraldelo (2002) em seu estudo sobre as representações de LM, perguntas que tematizam a LE, inevitavelmente, levarão os entrevistados a falarem da LM ou, pelo menos, a relacionar, contrapor e comparar tais línguas.

Para coleta dos registros e escolha dos entrevistados, estabelecemos que os sujeitos deveriam atender aos seguintes critérios:

- ser brasileiro;

- ter como LM o português do Brasil;

- ser falante fluente da LI;

-ter residido por, pelo menos, dois anos em um país que tenha como língua oficial a LI;

- não ser professor de LI como ocupação profissional primeira.

Os critérios foram estabelecidos de modo a possibilitar a compreensão do lugar ocupado pela LM na constituição identitária de sujeitos adultos, já constituídos na/pela LM, mas que entraram em contato com a LI em situações de imersão e que, portanto, também passaram a constituir e a serem constituídos por esta língua outra.

Os sujeitos cujos registros compõem esta pesquisa são engenheiros e atuam como professores e pesquisadores de uma instituição pública de ensino superior do Estado de São Paulo, bastante conhecida e respeitada no Brasil. A idade dos entrevistados varia de 44 a 49 anos. Todos eles receberam doutoramento em países onde a LI é a língua oficial (Estados Unidos, Inglaterra e outros países da Grã Bretanha) e, portanto, residiram por, pelo menos, quatro anos nesses lugares. Os pesquisados declararam ser fluentes na LI e utilizá-la com frequiência no seu dia-a-dia, principalmente para ler e escrever.

Assumindo que as manifestações do inconsciente se dão via simbólico e são materializadas na/pela língua (Coracini, 1997), é na superfície lingüística, ou seja, nas seqüências discursivas dos entrevistados, que procuraremos unidades significativas que possam revelar elementos do inconsciente, tais como lapsos, equívocos e atos falhos que manifestam o deslizamento de sentidos, podendo levar à compreensão da constituição identitária desses sujeitos.

\section{ANÁLISE DOS REGISTROS}

Nesta seção do trabalho, passaremos a analisar alguns "sintomas" ou conjuntos de regularidades enunciativas, segundo Foucault (1987), presentes nas respostas fornecidas ao questionário citado, como, por exemplo, o uso de estrangeirismos e estereótipos que, 
dentre outras marcas lingüístico-discursivas, apontam para a constituição identitária do sujeito bilíngüe.

\subsection{A presença de estrangeirismos: a LM como LE}

Em dois dos quatro questionários coletados para este estudo foi freqüente a presença de estrangeirismos, embora as respostas dos entrevistados tenham sido formuladas em português. O emprego de palavras da LI, mesmo havendo termos correspondentes na língua portuguesa $(\mathrm{LP})^{3}$, é revelador da constituição subjetiva do sujeito bilíngüe que, já afetado pela LI, incorpora em seu dizer na LM vocábulos da LI.

Passemos à materialidade lingüística. Na maioria das formulações proferidas pelos sujeitos $(\mathrm{S} 1)^{4}$ e (S2), em particular, deparamo-nos com diversas palavras da LI, como: mother tongue, fashion words, large screen TV, appointment, commitment, British English, accountability, accountable, chairman ${ }^{5}$. O curioso é que o uso desses estrangeirismos não foi "anunciado" nem mesmo percebido pelos entrevistados, ou seja, a mudança de vocábulos da LP para a LI ocorreu quase que automaticamente, denunciando que a constituição subjetiva do sujeito pesquisado, embora tenha se dado na LM, não é mais a mesma, pois também passou a ser constituída pela LI.

Em apenas uma das respostas fornecidas, S1 parece explicitar o motivo pelo qual empregou uma palavra em inglês:

Eu ficava feliz com a sensação de que as coisas funcionavam e que as pessoas assumiam suas responsabilidades. Aliás, acho que existe uma palavra em inglês sem boa tradução para o português, que é 'accountability'. Aqui no Brasil em geral, e porque não dizer no $\underline{X}^{6}$ em particular, é muito comum não localizarmos o sujeito 'accountable' por um determinado assunto.

Nota-se, com base na seqüência enunciativa acima, que S1 tem a sensação de não encontrar, na LP, um vocábulo com os mesmos efeitos de sentido provocados pelo vocábulo da LI (accountability), mesmo já tendo utilizado uma palavra equivalente em português (responsabilidade), no excerto abordado. Este acontecimento discursivo aponta para a falta constitutiva do sujeito de linguagem que, no entanto, só é sentida na LM. A LI passa a ser idealizada como completa, já que, imaginariamente, preenche as lacunas deixadas pela LM, que, por sua vez, parece não recobrir os mesmos sentidos das palavras da LI. Observa-se, portanto, que o contato com a LI desloca e confronta as marcas deixadas pela LM na identidade do sujeito em questão. É a LM que se apresenta como estrangeira, justamente por estar deslocada e permeada pelo imaginário e pelos sentidos produzidos pela LI, levando o enunciador a se movimentar, subjetivamente, entre o estranho da LM e o aparentemente familiar da LE. Assim, a LM se torna uma língua estrangeira ao sujeito

${ }^{3}$ Quando mencionarmos a língua portuguesa (LP), trata-se do português brasileiro.

${ }^{4} \mathrm{~S} 1,2,3 \ldots$ (= sujeito $1,2,3 \ldots$ ) serão os símbolos utilizados para enumerar os entrevistados da pesquisa.

${ }^{5}$ A tradução destas palavras para o português é, respectivamente: "língua materna", "palavras da moda/ atuais", "TV de tela grande", "encontro/reunião", "compromisso/comprometimento", "inglês britânico", "responsabilidade", "responsável", "presidente de uma sessão".

${ }^{6} \underline{X}$ é o símbolo utilizado para representar a instituição pública de ensino superior, onde o entrevistado trabalha. 
enunciador, junto à LI, que, por ser objeto de desejo e de identificações, lhe parece mais familiar do que sua própria língua (Kristeva, 1994).

Em uma outra sequiência enunciativa, S2 também emprega um vocábulo da LI em uma resposta fornecida em português:

Sem dúvida, o mais agradável é o profissionalismo com que encaram a vida, o chamado 'commitment' em fazer as coisas acontecerem...

É relevante salientarmos que tanto $\mathrm{S} 1$ como $\mathrm{S} 2$ empregam vocábulos da LI que funcionam quase como sinônimos (accountability; commitment). Nestes casos, os vocábulos da LP (responsabilidade; comprometimento) parecem não evocar os mesmos sentidos produzidos pelos vocábulos da LI, mesmo que, aparentemente, estejam numa relação de equivalência. Esse distanciamento se dá, pois o peso e o sentido das palavras, tanto na LP como na LI, estão diretamente relacionados ao imaginário dos sujeitos em relação aos países que falam tais línguas. Desse modo, falar de responsabilidade, num país de LI, imaginado como um modelo a ser seguido, não é o mesmo que falar de responsabilidade no país de origem. Daí a necessidade sentida pelo sujeito de linguagem de empregar um vocábulo da LI em sua formulação.

As considerações anteriores retomam a idéia de que o sujeito da LM que é investido por uma língua outra, no caso a LI, passa a falar de si e de sua "língua mãe" de um outro lugar. Isso parece nos indicar que, ao entrar em contato com outras discursividades, através da LI, o lugar ocupado pela LM, bem como a subjetividade do sujeito se modificam: o sujeito bilíngüe passa a ser constituído tanto pela LM como pela LE e, ao ser constituído por elas, também constitui a ambas.

\subsection{Saber uma língua: o desejo do lugar do outro}

No questionário utilizado para este estudo, foi pedido aos entrevistados que avaliassem o seu desempenho lingüístico na LM e na LE, muitas vezes confundido com o saber essas línguas e, ao fazê-lo, "permitiram" que a materialidade lingüística fizesse "saber" esse sujeito, apontando para sua constituição identitária.

Quando solicitado a atribuir uma pontuação de 1 a 5, de modo a indicar sua fluência na LI (vide anexo), S1 a avalia como 4,5 e justifica:

Suponho que fluente seja falar como um nativo, habilidade que não possuo.

Mais adiante, ao avaliar seu desempenho lingüístico na LM (LP) e na LI, S1 enuncia:

Não sei dizer ao certo. Sem ser petulante, acho que meu português está acima da média, para um nativo, e meu inglês acima da média, para um estrangeiro.

As sequiências proferidas pelo entrevistado denunciam alguns traços constitutivos de sua identidade enquanto bilíngüe. Para S1, a fluência na LI aparece condicionada ao "saber" do falante nativo; saber este considerado como padrão ou modelo de fluência absoluta. 
Contrariamente à sua consideração para a LE, ter um bom desempenho lingüístico na LP significa saber mais do que um falante nativo. Observa-se, portanto, que não há identificação do enunciador com o lugar ocupado pelo falante nativo da LM, já que aquele se distancia deste, deixando a lacuna do saber bem marcada e, até mesmo, intransponível. O desejo do enunciador é de se aproximar do lugar do falante nativo da LI, ao mesmo tempo em que se distancia do lugar do falante nativo da LM. Isso aponta para uma identificação não só com a língua do outro, mas com o outro que passa a ser constitutivo da identidade do sujeito bilíngüe, deslocando o lugar ocupado pela LM.

A pontuação que S1 atribuiu para a sua fluência na LI $(4,5)$, lembrando que esta pontuação pode variar de 1 a 5, também é bastante significativa, pois parece indicar que o sujeito está no "entre-lugar". Em outras palavras, ao se identificar com o outro, há a cisão de dois lugares distintos: S1 acredita saber a LM melhor do que a média dos falantes nativos, por outro lado, considera não saber a LI como um nativo, mas apenas como um estrangeiro. Conseqüentemente, como falante bilíngüe, S1 se torna estrangeiro em ambas as línguas e passa a ocupar um lugar distinto, situado no sem fronteiras do entre meio.

Apenas um dos entrevistados (S2) atribuiu a pontuação máxima (5) para a sua fluência na LI, o que sugere que este enunciador não só deseja se aproximar do lugar do outro, mas já acredita estar nesse lugar, distanciando-se, ainda mais, de sua língua e comunidade de origem. Essas considerações encontram respaldo em Revuz (1998:227) que afirma: "quanto melhor se fala uma língua, mais se desenvolve o sentimento de pertencer à cultura, à comunidade 'escolhida' e mais se experimenta um sentimento de deslocamento em relação à comunidade de origem". Essa citação, juntamente com os dizeres dos sujeitos, nos permite vislumbrar que, após entrar em contato com uma LE, a relação do falante com a língua que primeiramente o constituiu (a LM) jamais será a mesma, tendo em vista que suas matrizes identificatórias estarão em constante movimento, alterando suas representações em relação à LM e seus falantes.

As respostas fornecidas para a última pergunta do questionário de pesquisa também possibilitaram a apreensão de efeitos de sentido que apontam para o lugar da LM na constituição identitária do sujeito bilíngüe. Ao formularem suas respostas para a questão 15 (Considerando a hipótese de que haveria um tradutor/intérprete, numa situação formal no exterior, qual língua (inglês ou português) você escolheria para proferir uma palestra? Por quê?), três dos quatro entrevistados disseram, assertivamente, escolher a LI neste tipo de situação. Apenas um deles não conseguiu “camuflar” sua indecisão ao proferir tal escolha, deixando-a emergir na superfície lingüística:

Depende do que se entende por situação formal. Certamente em português. Se estamos falando de apresentações técnicas, não vejo muita diferença entre o português e o inglês. Agora, é claro que eu me sinto mais à vontade falando em português.

Nessa seqüência, o enunciador parece se deparar com a contradição que joga em suas palavras: a princípio, assegura que escolheria a LM; posteriormente, retoma o fio discursivo e põe em dúvida sua escolha e, por fim, volta a afirmar que seria a LM. Essa contradição, que ganha corpo em seu dizer, reflete a contradição inerente à sua subjetividade, denunciando, mais uma vez, que o sujeito está no "entre-lugar" ou entre línguas. 
Ainda em relação à mesma pergunta do questionário de pesquisa, S2 fornece a seguinte resposta:

Em inglês [...] mesmo que houvesse dificuldade de se expressar, devido a falta de vocabulário específico, gostaria de me expressar com minhas próprias palavras em inglês.

Observa-se que S2 assegura estar em um outro lugar em relação à LM: as palavras da LI já foram feitas suas próprias palavras e, portanto, através da LE e não mais da LM, S2 tem a ilusão de encontrar um lugar para se dizer e para se colocar enquanto sujeito.

Vale salientar que, ao mencionar a hipótese de haver dificuldades de se expressar na LI, devido à falta de vocabulário específico, S2 emprega o pronome de terceira pessoa se, em vez do pronome de primeira pessoa me. Essa inversão pronominal indica que a dificuldade de se expressar na LI existe, mas que não é do enunciador e sim do (O)utro.

S3, por sua vez, afirma: Inglês, pois evita lapsos de tradução. Este enunciado sugere que apenas a LM possibilita a ocorrência de lapsos e erros. Desse modo, a LI é imaginada como uma língua completa que evoca sentidos únicos e precisos, possibilitando o perfeito entendimento entre interlocutores, ao passo que a LP proporcionaria a dispersão dos sentidos desejados, provocando lapsos ou aparentes falhas de comunicação.

Com base nos registros anteriores, podemos dizer que a preferência por enunciar na LM ou na LE está relacionada ao conforto de se imaginar em um lugar reconhecido como seu, como familiar e não na língua propriamente dita. Portanto, havendo maior identificação com o lugar do outro e com a língua do outro, a LE pode ganhar estatuto de LM.

\subsection{Representações identitárias por meio de estereótipos}

Nos registros analisados, observamos uma regularidade no uso de estereótipos que possibilitou a apreensão de representações, não só em relação à LM e à LE, mas também em relação aos países e às sociedades que falam essas línguas.

Convém mencionarmos que os estereótipos permitem a manutenção discursiva que imprime, no sujeito de linguagem, memórias que são feitas de esquecimento, segundo Pêcheux (1990). Passemos à análise da superfície lingüística que ancora nossas considerações.

Em relação à pergunta 11 (O que mais o agradava na sociedade estrangeira?), três entrevistados empregaram estereótipos recorrentes em nossa sociedade sobre os países onde a LI é falada (Estados Unidos e Inglaterra, respectivamente) em suas respostas.

S1 formulou:

Eu ficava feliz com a sensação de que as coisas funcionavam e que as pessoas assumiam suas responsabilidades.

Mais adiante em sua resposta, o mesmo enunciador compara o país de LI com o Brasil:

Aqui no Brasil é muito comum não localizarmos o sujeito "accountable" por um determinado assunto. 
A partir dessas seqüências enunciativas, nota-se que o país de LI representa um modelo social e cultural a ser seguido, justamente por estar numa relação de oposição com o modelo representado pelo país de LM.

Ainda em relação à pergunta (11), S2 afirma:

\begin{abstract}
Sem dúvida, o que mais me agradava é o profissionalismo com que encaram a vida, o chamado "commitment" em fazerem as coisas acontecerem, em se perseguir as metas visando ir perseguindo os objetivos traçados...
\end{abstract}

Mais adiante na entrevista, S2 acrescenta:

Outro ponto que não posso deixar de mencionar é o fato de dois pontos estratégicos, na minha visão, serem responsáveis pela situação de superpotência desfrutada pelos Estados Unidos: [...] o processo de criar uma sociedade cuja economia 'funciona' [...] e de se investir na formação da mulher e do homem principalmente. Devido a esse segundo ponto, pode-se hoje ter uma vida digna exercendo-se qualquer profissão num país como aquele. Esses dois aspectos são particularmente importantes quando se contrasta com o nosso cenário político econômico.

Pudemos observar, tal como materializam as formulações, que as "verdades" sobre os países de LM e de LE são construídas por meio de estereótipos que circulam no senso comum e que evocam um imaginário em relação ao falante nativo de cada língua.

Após apontar algumas diferenças que distanciariam os dois países, S2 faz uma observação:

Não quero que fique transparecendo que não sou crítico da política internacional americana, de seu isolacionismo e intervencionismo atual, e que não reconheço os imensos problemas que eles têm de resolver...

Nessa seqüência enunciativa, a presença da denegação, vislumbrada através da repetição da negação (não), denuncia o imaginário do sujeito em relação à sociedade e ao país que fala a LI, embora este não se dê conta disso. Quando o sujeito diz não querer transparecer que não é crítico da política internacional, é justamente este comportamento não crítico e de identificação com o outro que se materializa em seu dizer. Portanto, mesmo negando um comportamento, o enunciador acaba por reforçá-lo, graças ao deslizamento de sentidos que seu dizer produz.

S1 também emprega estereótipos para comentar sobre sua adaptação no país estrangeiro:

[...] Não acredito nesses estereótipos do tipo 'os americanos são frios e distantes' ou o que quer que seja. Depois a universidade é um ambiente pluralista em que esse conceito de país se perde um pouco.

O que nos chamou a atenção nas observações trazidas por S1 e S2 é que, ao falar do outro, eles se revelam na/pela língua, isto é, enquanto julgam fazer determinado uso da língua e controlar o seu dizer, trazem à tona certos traços constitutivos de sua identidade, 
por meio de regularidades enunciativas que denunciam a identificação com os países de LI e o distanciamento em relação ao país de origem.

De um modo geral, pudemos observar que o encontro de duas culturas, caracterizadas pelos enunciadores como "distantes" e distintas, provoca um sentimento de estranhamento em relação à própria cultura, na qual não conseguem se espelhar. Por outro lado, a LI, seus falantes e sua cultura são imaginados como ideais, em detrimento e oposição à própria cultura e língua.

Em suma, as sequiências enunciativas abordadas se aproximam por possibilitarem uma manutenção discursiva, mesmo que o sujeito já tenha vivido no exterior. Dito de outro modo, a experiência dos sujeitos bilíngües é relatada não só, mas predominantemente, pelo emprego de estereótipos que direcionam seus relatos e que os marcam mais fortemente do que a própria vivência no exterior. Assim sendo, os entrevistados parecem não singularizar essa experiência, que, muito freqüentemente, é relatada através de imagens e conceitos pré-construídos.

\section{CONSIDERAÇÕES FINAIS}

A partir de alguns "sintomas" ou regularidades nas formulações dos entrevistados, tais como: o emprego de estrangeirismos em respostas formuladas na LM; a freqüente comparação entre a LM e a LE; a presença de estereótipo(s) para caracterizar a LM, a LE e os falantes nativos de cada língua; dentre outras, foi possível observar o lugar ocupado pela LM que, por sua vez, aponta para a constituição identitária do sujeito bilíngüe e para a identificação não só com a língua do outro, mas com o outro (falante nativo).

Embora os sujeitos pesquisados tenham tido suas subjetividades constituídas na/pela LM, ao entrarem em contato com uma LE, a relação desses sujeitos com a língua mãe se modifica, tendo em vista que suas matrizes identificatórias estarão em constante movimento. Conseqüentemente, o lugar da LM na constituição identitária do sujeito bilíngüe jamais será o mesmo, pois sua subjetividade passa a ser constituída na/pela relação de contraposição entre o lugar de interdição e da falta, ocupado pela LM, e o lugar idealizado como "completo", ocupado pela LE.

O que podemos concluir, a partir da análise dos registros, é que o sujeito bilíngüe parece estar no "entre-lugar", isto é, entre línguas e identidades. Assim sendo, o sujeito se torna bilíngüe ou estrangeiro em ambas as línguas, já que o contato entre a LM e a LE possibilita a ruptura e o deslocamento de lugares e de identidades já constituídas na/pela LM, revelando um outro saber sobre esse sujeito, através dos desejos recalcados que se dão a escutar via simbólico.

Algumas considerações propostas por Capinha (2000:136) nos permitem adentrar esse sentimento de estar entre línguas e culturas, bastante freqüente nas seqüências enunciativas abordadas. Nas palavras da autora, "este estar entre (cá e lá) aponta para um real de confrontos difusos entre o concreto e o imaginário, um real sempre subjetivo que carrega a impossibilidade de ser ou 'o mesmo' ou 'o Outro', apenas”.

Em última instância, podemos afirmar que o sujeito que está entre línguas, no caso o bilíngüe, é pulverizado por identidades híbridas e múltiplas que advêm das identificações 
com a língua do outro e resultam da impossibilidade de se traçar fronteiras entre a LM e a LE, bem como de (de)marcar os lugares que estas ocupam na constituição do sujeito.

\section{REFERÊNCIAS BIBLIOGRÁFICAS}

CAPINHA, G. (2000). A poesia dos emigrantes portugueses no Brasil: ficções críveis no campo da(s) identidade(s). In. Identidades: Estudos de cultura e poder (Capinha \& Feldman-Bianco [orgs.]). São Paulo: Editora Hucitec.

CHNAIDERMAN, M. (1998). Língua(s)-linguage(ns) - identidade(s) - movimento(s): uma abordagem psicanalítica. In. Língua(gem) e Identidade: Elementos para uma discussão no campo aplicado (Signorini, I. [org.]). Campinas, SP: Mercado de Letras. São Paulo: FAPESP.

CORACINI, M. J. (1997). Língua estrangeira e língua materna: uma questão de sujeito e identidade. In Letras \& Letras, Uberlândia, MG, vol.14, $\mathrm{n}^{\circ}$ 1, p.153-169.

COSTA, A. (2001). Corpo e Escrita: relações entre memória e transmissão da experiência. Rio de Janeiro, RJ: Relume Dumará.

FOUCAULT, M. (1987). A arqueologia do saber. $3^{\text {a }}$. ed. (L. F. B. Neves [trad.]). Rio de Janeiro, RJ: Forense Universitária.

GHIRALDELO, C. M. (2002). As representações de língua materna: entre o desejo de completude e a falta do sujeito. Tese de Doutorado em Lingüística Aplicada - IEL/ UNICAMP.

HALL, S. (2000). A identidade Cultural na Pós-Modernidade. Rio de Janeiro, RJ: DP\&A Editora.

KRISTEVA, J. (1994). Estrangeiros para nós mesmos. (M. C. Carvalho Gomes [trad.]). Rio de Janeiro, RJ: Editora Rocco.

MELMAN, C. (1992). Imigrantes: incidências subjetivas das mudanças de língua e país. (R. Pereira [trad.]). São Paulo, SP: Editora Escuta.

MILNER, J. C. (1987). O amor da língua. (A. C. Jesuíno [trad.]). Porto Alegre: Artes Médicas.

PÊCHEUX, M. (1990). O discurso: Estrutura ou Acontecimento. (Eni Orlandi [trad.]). Campinas, SP: Editora Pontes.

PEREIRA DE CASTRO, M.F. (1998). Sobre a interpretação e os efeitos da fala da criança. In Letras de hoje. Porto Alegre, vol. $33, \mathrm{n}^{\circ}$ 2, p. 81-87.

REVUZ, C. (1998). A língua estrangeira entre o desejo de um outro lugar e o risco do exílio. In Linguagem e Identidade: Elementos para uma discussão no campo aplicado. (Signorini [org.]). Campinas, SP: Mercado de Letras. São Paulo: FAPESP.

SILVA, T. [org.] (2000). Identidade e diferença: a perspectiva dos estudos culturais. Petrópolis, RJ: Vozes. 


\section{ANEXO}

\section{QUESTIONÁRIO DE PESQUISA}

Nome (opcional):

Idade: Local de nascimento:

1) Curso de Graduação: Instituição e local: Término:

2) Pós-Graduação: Área(s) de conhecimento: Instituição e local: Término:

3) Área(s) de atuação profissional:

4) Em qual(is) país(es) você já residiu e quanto tempo permaneceu em tal(is) lugar(es)?

5) Atribua a pontuação de 1 a 5 à(s) língua(s) estrangeira(s) que você conhece, considerando que 1 equivale a "conhecimentos básicos" e 5, a "fluente".

6) Com que freqüência, no seu dia-a-dia, você usa a língua inglesa para falar e para escrever?

7) Como você avalia seu desempenho lingüístico na língua materna (português) e na língua estrangeira (inglês)?

8) Você também atua (ou já atuou) como professor de inglês, tradutor ou intérprete? Comente sobre essa experiência profissional.

9) Considerando que você já residiu no exterior, diga de que maneira esta experiência contribuiu, não apenas para sua proficiência em língua inglesa, mas, especialmente, para o seu modo de ver as sociedades brasileira e a estrangeira (do país onde você residiu).

10) Quando você residiu no exterior para a realização do doutorado, o que mais o incomodava na sociedade estrangeira? Por quê?

11) E o que mais o agradava? Por quê?

12) Você se lembra o que mais lhe impressionou quando chegou no país onde faria seu doutorado? Por quê?

13) Como foi sua adaptação no país estrangeiro? Fale um pouco sobre isso. 
14) Quando você está em um país de língua inglesa, como se sente em relação à língua e à cultura de tal país? Como é sua interação com os falantes nativos do inglês?

15) Considerando a hipótese de que haveria um tradutor/intérprete, numa situação formal no exterior, qual língua (inglês ou português) você escolheria para proferir uma palestra? Por quê? 